\title{
The role of inferior petrosal sinus sampling in ACTH-dependent Cushing's syndrome: review and joint opinion statement by members of the Italian Society for Endocrinology, Italian Society for Neurosurgery, and Italian Society for Neuroradiology
}

\author{
Francesca Pecori Giraldi, MD, ${ }^{1,2}$ Luigi Maria Cavallo, MD, PhD, ${ }^{3}$ Fabio Tortora, MD, PhD, ${ }^{4}$ \\ Rosario Pivonello, MD, PhD, ${ }^{6}$ Annamaria Colao, MD, PhD, ${ }^{6}$ Paolo Cappabianca, MD, ${ }^{3}$ \\ and Franco Mantero, MD, PhD, ${ }^{5}$ on behalf of the Altogether to Beat Cushing's Syndrome Group
}

\begin{abstract}
${ }^{1}$ Department of Clinical Sciences and Community Health, University of Milan; ${ }^{2}$ Neuroendocrine Research Laboratory, Istituto Auxologico Italiano, Milan; ${ }^{3}$ Division of Neurosurgery, Department of Neurosciences and Reproductive and Odontostomatological Sciences, and ${ }^{6}$ Department of Clinical Medicine and Surgery, University of Naples Federico Il; ' ${ }^{4}$ Department of Neuroradiology, "Magrassi Lanzara" Clinical-Surgical Department, Second University of Naples, Naples; and "Endocrinology Unit, Department of Medicine, University of Padua, Italy
\end{abstract}

\begin{abstract}
In the management of adrenocorticotropic hormone (ACTH)-dependent Cushing's syndrome, inferior petrosal sinus sampling (IPSS) provides information for the endocrinologist, the neurosurgeon, and the neuroradiologist. To the endocrinologist who performs the etiological diagnosis, results of IPSS confirm or exclude the diagnosis of Cushing's disease with $80 \%-100 \%$ sensitivity and over $95 \%$ specificity. Baseline central-peripheral gradients have suboptimal accuracy, and stimulation with corticotropin-releasing hormone $(\mathrm{CRH})$, possibly desmopressin, has to be performed. The rationale for the use of IPSS in this context depends on other diagnostic means, taking availability of CRH and reliability of dynamic testing and pituitary imaging into account. As regards the other specialists, the neuroradiologist may collate results of IPSS with findings at imaging, while IPSS may prove useful to the neurosurgeon to chart a surgical course. The present review illustrates the current standpoint of these 3 specialists on the role of IPSS.
\end{abstract}

http://thejns.org/doi/abs/10.3171/2014.11.FOCUS14766

KEY WORDS inferior petrosal sinus sampling; Cushing's disease; Cushing's syndrome; diagnosis; pituitary adenoma; pituitary surgery; pituitary imaging

I NFERIOR petrosal sinus sampling (IPSS) is an important procedure in the diagnostic work-up of Cushing's syndrome. Evidence accrued over the past 3 decades lays the foundation for its rational use in various clinical settings.

\section{Evidence on the Use of Petrosal Sinus Sampling}

Inferior petrosal sinus sampling entered the diagnostic work-up of Cushing's syndrome after the seminal National Institutes of Health (NIH) publication by Oldfield et al. $^{41}$ in 1991, which followed upon a paper by Findling et al., ${ }^{14}$ published some 10 years earlier, pioneering petrosal venous sampling in Cushing's disease and ectopic adrenocorticotropic hormone (ACTH) secretion. The NIH paper described results obtained in over 200 patients and asserted that the maximum ratio of ACTH concentrations in inferior petrosal sinus plasma to concentrations in peripheral-blood plasma (central/peripheral ratio), either at baseline sampling or after administration of corticotropin-releasing hormone $(\mathrm{CRH})$, provided $100 \%$ diagnostic accuracy for both pituitary and ectopic ACTH-secreting tumors. ${ }^{41}$ Subsequent studies-including some from the NIH itself-showed, however, that the diagnostic accuracy is not absolute and both false-negatives (lack of a central/

ABBREVIATIONS ACTH = adrenocorticotropic hormone, or corticotropin; $\mathrm{CRH}=$ corticotropin-releasing hormone; IPSS = inferior petrosal sinus sampling; NIH = National Institutes of Health.

SUBMITTED October 1, 2014. ACCEPTED November 26, 2014

INCLUDE WHEN CITING DOI: 10.3171/2014.11.FOCUS14766.

DISCLOSURE The authors report no conflict of interest concerning the materials or methods used in this study or the findings specified in this paper. 
peripheral gradient in patients with Cushing's disease), and false positives (presence of a central/peripheral gradient in patients with ectopic ACTH secretion) occur.

Table 1 describes publications reporting on the use of IPSS in at least 20 patients, and, as can be observed, false negatives may occur in 10\%-15\% of patients, with a higher prevalence on baseline, unstimulated ACTH levels. In detail, sensitivity of baseline central/peripheral gradients ranges from $54 \%$ to $96 \%$, whereas $\mathrm{CRH}$-stimulated gradients achieve $81 \%-100 \%$ sensitivity. These series represent data collected from centers in many areas of the world, thus false negatives are not a problem confined to single centers or areas. The main cause of absent ACTH gradient in patients harboring a pituitary ACTH-secreting tumor are unilateral or bilateral anatomical variants in the petrosal venous system. Shiu et al. originally classified 4 variants. ${ }^{56}$ In Type I, the most common variant, the petrosal sinus drains directly into the internal jugular vein; in Type II, the petrosal sinus drains into the anterior condylar vein, thus into both the jugular vein and the vertebral venous plexus; in Type III, the petrosal sinus is plexiform, and a network of small vessels drains into the internal jugular vein and the vertebral venous plexus; in Type IV, the petrosal sinus drains directly into the vertebral venous plexus via the condylar veins, without connection to the jugular vein. This classification was subsequently modified, and the most recent version describes 6 variants, with emphasis on the petrosal-jugular junction. ${ }^{36}$ These variants also explain the less than $100 \%$ success rate of bilateral petrosal cannulation and sampling (Table 1). Sampling from jugular veins has been employed with some success ${ }^{20}$ and appears a viable, fallback option if technical difficulties are encountered en route to the petrosal sinuses. ${ }^{2,28,54,67} \mathrm{On}$ the other hand, cavernous sinus sampling does not appear to be superior to IPSS. ${ }^{31}$ False-negative results may also be due to the variability in the tumoral corticotrope secretory pattern, ${ }^{47}$ and $\mathrm{ACTH}$ secretion by the adenoma into the petrosal sinuses in a given moment might not reach the expected 2- to 3-fold excess compared with peripheral concentrations. Ensuring clear hypercortisolism during sampling as well as using lower central/peripheral gradients ${ }^{20,54}$ may overcome this problem.

TABLE 1. Summary of case series reporting on IPSS in at least 20 patients*

\begin{tabular}{|c|c|c|c|c|c|c|}
\hline \multirow[b]{2}{*}{ Authors \& Year } & \multirow[b]{2}{*}{ Location } & \multicolumn{2}{|c|}{ Cushing's Disease $†$} & \multicolumn{2}{|c|}{ Ectopic ACTH $\ddagger$} & \multirow{2}{*}{$\begin{array}{l}\text { Successful } \\
\text { Cannulation }\end{array}$} \\
\hline & & Baseline & Post-CRH & Baseline & Post-CRH & \\
\hline Oldfield et al., 1991 & Bethesda & $205 / 215(95 \%)$ & $203 / 203(100 \%)$ & $20 / 20$ & $17 / 17$ & $99 \%$ \\
\hline Findling et al., 1991 & Milwaukee & $18 / 20(90 \%)$ & $17 / 18(94 \%)$ & $9 / 9$ & $6 / 6$ & $93 \%$ \\
\hline Tabarin et al., 1991 & Bordeaux & $18 / 22(82 \%)$ & $22 / 22(100 \%)$ & $5 / 5$ & $5 / 5$ & $89 \%$ \\
\hline López et al., 1996 & Madrid & $27 / 30(90 \%)$ & $22 / 25(88 \%)$ & & & $94 \%$ \\
\hline Landolt et al., 1994 & Zurich & $33 / 38(87 \%)$ & $37 / 38(95 \%)$ & & & - \\
\hline Zarilli et al., 1995 & Naples & $12 / 22(54 \%)$ & $19 / 22(86 \%)$ & $4 / 4$ & $4 / 4$ & $85 \%$ \\
\hline Booth et al., 1998 & Toronto & \multicolumn{2}{|c|}{$24 / 26(84 \%)$} & & & $91 \%$ \\
\hline Teramoto et al., 1998 & Tokyo & $27 / 35(77 \%)$ & & $5 / 5$ & & - \\
\hline Kaltsas et al., 1999 & London & $50 / 68(72 \%)$ & $64 / 69(93 \%)$ & $6 / 6$ & $6 / 6$ & $73 \%$ \\
\hline Invitti et al., $1999^{23}$ & Italy§ & $69 / 85(81 \%)$ & $65 / 76(85 \%)$ & $9 / 10$ & $10 / 10$ & - \\
\hline Bonelli et al., 2000 & Mayo Clinic & $48 / 54(89 \%)$ & $47 / 54(87 \%)$ & $9 / 9$ & $8 / 9$ & $87 \%$ \\
\hline Wiggam et al., 2000 & Belfast & $36 / 44(82 \%)$ & & $1 / 1$ & & - \\
\hline Lefournier et al., 2003 & Grenoble & $71 / 74(96 \%)$ & $74 / 74(100 \%)$ & $12 / 12$ & $10 / 12$ & - \\
\hline Liu et al., 2004 & Cleveland & $39 / 42(93 \%)$ & $21 / 22(95 \%)$ & $9 / 9$ & $7 / 7$ & - \\
\hline Ilias et al., 2004 & Bethesda & $58 / 65(89 \%)$ & $59 / 65(91 \%)$ & $13 / 13$ & $13 / 13$ & $92 \%$ \\
\hline Kalgikar et al., 2005 & Mumbai & $23 / 34(68 \%)$ & & $4 / 4$ & & $100 \%$ \\
\hline Kaskarelis et al., 2006 & Athens & \multicolumn{2}{|c|}{$57 / 63(90 \%)$} & $12 / 12$ & $12 / 12$ & $81 \%$ \\
\hline Jehle et al., 2008 & New York & & $103 / 105(98 \%)$ & & & $97 \%$ \\
\hline Daousi et al., 2010 & Liverpool & $21 / 24(87 \%)$ & $21 / 24(87 \%)$ & $2 / 2$ & $2 / 2$ & $69 \%$ \\
\hline Shi et al., 2011 & Shanghai & $57 / 64(89 \%)$ & & $4 / 5$ & & $100 \%$ \\
\hline Mulligan et al., 2011 & Cleveland & $33 / 35(94 \%)$ & $33 / 35(94 \%)$ & & $1 / 1$ & - \\
\hline Andereggen et al., 2012 & Bern & $17 / 20(85 \%)$ & $19 / 20(95 \%)$ & $2 / 3$ & $2 / 3$ & $96 \%$ \\
\hline Sheth et al., 2012 & Boston & \multicolumn{2}{|c|}{$194 / 296(94 \%)$} & \multicolumn{2}{|c|}{$9 / 11$} & $83 \%$ \\
\hline Grant et al., 2012 & London & & $67 / 83(81 \%)$ & & $10 / 10$ & - \\
\hline Wind et al., 2013 & Bethesda & $467 / 501(93 \%)$ & $487 / 500(97 \%)$ & & & $99 \%$ \\
\hline
\end{tabular}

* Some series from the same center might contain duplicate data. The most recent series from a given center is listed in case of multiple publications on the same patient database. Diagnostic criteria as defined by Oldfield et al..41 Cushing's disease is defined as a central/peripheral baseline ACTH gradient $\geq 2$ or post-CRH $\geq 3$; ectopic ACTH secretion is defined as a central/peripheral baseline ACTH gradient $<2$ or post-CRH $<3$.

$\dagger$ Number of true positives over total number of patients with Cushing's disease tested (sensitivity).

$\ddagger$ Number of true negatives over total number of patients with ectopic ACTH secretion tested.

$\S$ Multicenter study. 
In addition to false negatives, a small portion of patients bearing an extrapituitary ACTH-secreting tumor present an unexpected central/peripheral ACTH gradient. A scattering of cases have been reported in major case series (Table 1) as well as in individual case reports., ${ }^{930,42,58,62,69}$ Overall, although the paucity of reported cases allows only an approximate calculation, the specificity of IPSS may be estimated at $90 \%-95 \%$. In a number of these cases, patients were subjected to transsphenoidal surgery, but the postoperative course suggested an ectopic source, and the causative lesion-in some cases already evident prior to pituitary surgery but deemed incidental at the time-was subsequently removed. Some tumors were documented to secrete both ACTH and CRH, ${ }^{30,69}$ a credible explanation for false-positive results, or were located close to the pituitary (e.g., esthesioneuroblastoma or sphenoidal sinus ectopic pituitary adenoma). ${ }^{21,62}$ It has been suggested that false positives could be due to intermittent hypercortisolism and sampling performed by chance in the eucortisolemic state, ${ }^{68}$ this implies that normal corticotropes rapidly recover their secretory pattern as soon as cortisol levels decrease, which contrasts, however, with long-standing secondary adrenal insufficiency after curative surgery for Cushing's syndrome due to any cause. For the most part, the cause of false-positive IPSS results remained elusive in patients with proven ectopic ACTH-secreting tumors.

Altogether, given the different prevalence of the 2 etiologies of ACTH-dependent Cushing's syndrome, with pituitary outnumbering ectopic secretion by $4-5$ to 1 , it appears evident that any patient without a central/peripheral gradient is still more likely to harbor a pituitary rather than an extra-pituitary tumor. Indeed, this justified transsphenoidal surgery in all those patients in whom IPSS results were proven false by the success of pituitary surgery. In these patients, dynamic testing and/or pituitary imaging pointed toward a pituitary origin and no extra-pituitary lesion was evident, thus supporting pituitary exploration.

The data reported so far rest on measurement of ACTH in the petrosal sinus, the most rational approach to confirming the presence of a corticotrope tumor; however, the tumor might secrete additional pituitary-derived peptides, such as growth hormone, prolactin, thyroid-stimulating hormone, alpha subunit, alternative proopiomelanocortin breakdown products (e.g., $\beta$-endorphin), ${ }^{50}$ or non-pituitary-derived factors (e.g., atrial natriuretic factor, interleukin-1 receptor antagonist, tumor necrosis factor alpha, or parathyroid hormone-related protein). ${ }^{34,65}$ Of these, only prolactin has proven of some use to attest to successful catheterization. ${ }^{15}$ Furthermore, in some patients without a central/peripheral gradient, normalizing the ACTH ratio by prolactin pointed toward a pituitary origin,,${ }^{18,53}$ thus reversing a false-negative result. However, proposed cutoffs for pituitary or ectopic secretion vary, and an area of uncertainty remains..$^{52}$ The prolactin inter-sinus ratio has been used to predict tumor localization within the pituitary, as it is known that the ACTH inter-sinus ratio is correct in less than $70 \%$ of cases. ${ }^{67}$ However, even with the prolactin-adjusted ACTH ratio, tumor site prediction is by no means absolute. ${ }^{39}$ Altogether, the measurement of prolactin proved useful in selected cases, mostly with negative gradients, but whether it provides meaningful, adjunctive information and should be assessed routinely remains to be established.

As regards baseline versus stimulated ACTH gradients, as mentioned above, most series report greater sensitivity after CRH stimulation, thus supporting its use during IPSS to maximize diagnostic accuracy. Nevertheless, $\mathrm{CRH}$ is not readily available worldwide, and desmopressin, an alternative stimulant for tumoral ACTH secretion, ${ }^{37,49}$ has been employed. Approximately 150 patients with Cushing's disease tested with desmopressin have been reported on so far, $4,10,33$ with the results showing sensitivity comparable to that of CRH stimulation (i.e., 90\%-97\%). Stimulation with desmopressin and $\mathrm{CRH}$ together, performed to amplify corticotrope responses, identified a central/peripheral ACTH gradient in 46 of 47 patients with Cushing's disease. ${ }^{63}$ The use of desmopressin however might mandate additional precautions during the sampling procedure, as this agent is a known hemostatic and causes release of von Willebrand factor as well as other factors of the coagulatory cascade in patients with Cushing's disease. ${ }^{46}$

In this context, it is worth recalling that IPSS is an invasive maneuver that requires specific expertise to achieve successful bilateral cannulation and accurate and coordinated blood sampling and minimize untoward effects. Minor complaints during or after petrosal sampling have included tinnitus or otalgia $(1 \%-2 \%)$ and groin swelling or hematoma (2\%-3\%). More serious complicationsboth neurological (nerve palsy [1\%], subarachnoid hemorrhage, brainstem infarction, or contrast extravasation) and peripheral (e.g., pulmonary and deep vein thromboembolism) - have been reported but appear extremely rare. . $^{35,61}$ Developments in endovascular materials, such as smaller, hydrophilic catheters and microcatheters and pressurized sacks for continuous catheter flushing, may minimize the risks of thromboembolic and hemorrhagic events. Unilateral femoral vein puncture using 9-Fr sheaths may reduce groin complications in obese patients. ${ }^{43}$

\section{Rationale for the Use of Petrosal Sinus Sampling}

Petrosal sinus sampling can yield 2 different types of evidence: 1) it can differentiate between pituitary and ectopic tumoral ACTH secretion, and 2) it can provide clues as to the site of a patient's pituitary adenoma (i.e., midline or right or left of midline). The endocrinologist is obviously interested in achieving the correct differential diagnosis, whereas the neurosurgeon also benefits from any information as to the location of the adenoma.

Series reporting on the use of IPSS have adopted different strategies-for example, performing the procedure in any patient with ACTH-dependent Cushing's syndrome, only in patients with ACTH-dependent Cushing's syndrome and equivocal responses to dynamic testing (CRH stimulation and/or high-dose dexamethasone suppression), or only in patients in whom pituitary imaging failed to visualize an adenoma, regardless of results of dynamic testing. In patients with clear-cut responses to CRH and/ or 8-mg dexamethasone and some evidence of a pituitary adenoma, IPSS is usually not performed.

These strategies all have pros and cons. The abridged 
strategy for IPSS in any patient with Cushing's syndrome, detectable ACTH levels, and normal or equivocal findings on pituitary imaging is based on an epidemiological premise - that is, that Cushing's disease is by far the more likely diagnosis and that dynamic testing does not add to (and may even detract from) this a priori probability. Arguing against this approach is the risk of false negatives at IPSS, which-in the absence of supportive results from dynamic testing-may divert the patient from appropriate surgery. Furthermore, IPSS may prove inconclusive due to failure to correctly cannulate the petrosal sinuses (see Table 1); indeed, a large series detailing unsuccessful IPSS showed that a pituitary source was detected at surgery in over $85 \%$ of cases..$^{54}$ Of note, this strategy has even led to petrosal sampling in patients with adrenal Cushing's syndrome and unsuppressed plasma ACTH concentrations. ${ }^{28,54}$

In other series, IPSS was performed in patients with equivocal responses to dynamic testing, usually to confirm the diagnosis of Cushing's disease. ${ }^{22,60} \mathrm{CRH}$ stimulation has proven the most accurate, non-invasive approach to differentiate between pituitary and ectopic tumors, ${ }^{45,48}$ but $\mathrm{CRH}$ is expensive and not widely available. In contrast, high-dose dexamethasone suppression can be easily performed but is less accurate. Indeed, to obtain certainty of pituitary disease, the criterion for cortisol suppression needs to be set at $80 \%-90 \%$ of pretest concentrations, and this, in turn, increases the number of non-suppressors among patients with Cushing's disease..$^{12,17,23}$ On the other hand, the likelihood of false-positive responses to both the CRH test and the 8-mg dexamethasone test in patients with ectopic ACTH secretion using appropriate response criteria appears very low., ${ }^{1,21,40,64}$ Of note, falsepositive IPSS results have been reported in patients with false-positive responses to these tests..$^{58,62,69}$

Lastly, IPSS has been used in patients with ACTHdependent Cushing's syndrome who did not present a clear pituitary lesion, even though testing was indicative of a pituitary lesion. This approach is burdened by the low prevalence of visible pituitary tumors in patients with Cushing's disease; indeed, even the most sensitive pituitary imaging techniques proved negative in $20 \%-50 \%$ of patients in whom an ACTH-secreting adenoma was confirmed by surgery. ${ }^{44}$ Furthermore, incidental pituitary lesions have been described in the general population, ${ }^{19}$ in patients with ectopic ACTH secretion, ${ }^{1,3,21}$ and in patients with Cushing's disease. ${ }^{8}$ With respect to this latter group, this observation is supported by the fact that concordance between adenoma site prediction at imaging and location at pituitary surgery is by no means absolute (i.e., has been reported to be as low as 50\%). ${ }^{8}$ Reported data refer to imaging performed mostly prior to the advent of newer, more sensitive MRI equipment (1.5-, 3-, and in the future even 7-T units), and findings could therefore change over the next few years. Whether the increased sensitivity for these small adenomas is offset by an increased detection rate of pituitary incidentalomas remains to be seen.

On the other hand, in patients with a high likelihood of Cushing's disease and without visible evidence of a pituitary adenoma, IPSS may provide adjuvant information to the neurosurgeon rather than be required to complete the diagnostic work-up. The main challenge in these pa- tients is in fact careful exploration of the pituitary gland in search of a microadenoma. Most authors agree that IPSS should, at most, suggest the side of the gland to be explored first; however, a thorough exploration is usually recommended even after an initial finding because contralateral ACTH-secreting pituitary adenomas have been described. ${ }^{13}$ As to technical issues, pituitary gland exploration requires specific training: one possible, quite common pitfall is to interpret small seepage due to pituitary tissue manipulation or squeezing as a microadenoma. ${ }^{51}$ Color and consistency of the tumor are easily recognized by the experienced neurosurgeon, as ACTH-secreting adenomas are usually whitish and soft. Further, care should be taken during tumor collection to avoid inadvertent tumor specimen aspiration. Filters in the suction system may be of use to collect aspirated surgical specimens, but these are often too small for pathology, thus definite proof of tumor removal is not obtained. No study has yet evaluated whether more extensive pituitary exploration due to misleading or absent lateralization at IPSS is linked to postsurgical hypopituitarism, but this is not an unreasonable assumption. This argument may prove particularly significant in children with Cushing's disease, in whom pituitary imaging is often inconclusive. ${ }^{25}$

As regards the influence of IPSS on remission rates, both older ${ }^{5}$ and more recent ${ }^{24}$ studies have shown that outcome of pituitary surgery is comparable in patients who have or have not undergone IPSS prior to surgery. Moreover, detection of the pituitary adenoma and remission were also extensively proven in patients with negative central/peripheral ratios (see Table 1); indeed, proof of Cushing's disease by either was a prerequisite to assert a false-negative result. Thus, negative IPSS does not appear to affect likelihood of remission.

\section{Conclusions}

The endocrinologist, neuroradiologist, and neurosurgeon have different but overlapping expectations from IPSS. The endocrinologist might need to confirm the diagnosis, the neuroradiologist to locate the adenoma, and the neurosurgeon to direct pituitary surgery. Altogether, these requirements establish the framework for the role of IPSS in Cushing's syndrome, as discussed by members of the Italian Society for Endocrinology (SIE), Italian Society for Neurosurgery (SINCh), and Italian Society for Neuroradiology (AINR) during the meeting "Altogether to Beat Cushing's Syndrome."

\section{Acknowledgments}

Participants in the "Altogether to Beat Cushing's Syndrome (ABC)" meeting, held in Sorrento, Italy, in May 2014, were Nora Albiger, Carlo Alviggi, Alberto G. Ambrogio, Giorgio Arnaldi, Emanuela Arvat, Roberto Baldelli, Marco Boscaro, Michela Campo, Salvatore Cannavò, Francesco Cavagnini, Iacopo Chiodini, Salvatore Maria Corsello, Alessia Cozzolino, Monica Di Leo, Maria Cristina De Martino, Carolina Di Somma, Katherine Esposito, Diego Ferone, Federico Gatto, Roberta Giordano, Dario Giugliano, Chiara Graziadio, Franco Grimaldi, Davide Iacuaniello, Andrea Isidori, Ioannis Karamouzis, Andrea Lenzi, Paola Loli, Massimo Mannelli, Paolo Marzullo, Valentina Morelli, Rosa Maria Paragliola, Gabriele Parenti, Claudia Pivolenno, Giuseppe Reimondo, Carla Scaroni, 
Scillitani Alfredo, Chiara Simeoli, Antonio Stigliano, Miriam Talco, Massimo Terzolo, Laura Trementino, Claudio Urbani, Giovanni Vitale, Maria Chiarza Zatelli.

\section{References}

1. Alexandraki KI, Grossman AB: The ectopic ACTH syndrome. Rev Endocr Metab Disord 11:117-126, 2010

2. Andereggen L, Schroth G, Gralla J, Seiler R, Mariani L, Beck J, et al: Selective inferior petrosal sinus sampling without venous outflow diversion in the detection of a pituitary adenoma in Cushing's syndrome. Neuroradiology 54:495503, 2012

3. Andrioli M, Pecori Giraldi F, De Martin M, Cattaneo A, Carzaniga C, Cavagnini F: Differential diagnosis of ACTHdependent hypercortisolism: imaging versus laboratory. Pituitary 12:294-296, 2009

4. Belli S, Oneto A, Mendaro E: [Bilateral inferior petrosal sinus sampling in the differential diagnosis of ACTH-dependent Cushing's syndrome.] Rev Med Chil 135:1095-1102, 2007 (Span)

5. Bochicchio D, Losa M, Buchfelder M: Factors influencing the immediate and late outcome of Cushing's disease treated by transsphenoidal surgery: a retrospective study by the $\mathrm{Eu}-$ ropean Cushing's Disease Survey Group. J Clin Endocrinol Metab 80:3114-3120, 1995

6. Bonelli FS, Huston J III, Carpenter PC, Erickson D, Young WF Jr, Meyer FB: Adrenocorticotropic hormone-dependent Cushing's syndrome: sensitivity and specificity of inferior petrosal sinus sampling. AJNR Am J Neuroradiol 21:690696, 2000

7. Booth GL, Redelmeier DA, Grosman H, Kovacs K, Smyth HS, Ezzat S: Improved diagnostic accuracy of inferior petrosal sinus sampling over imaging for localizing pituitary pathology in patients with Cushing's disease. J Clin Endocrinol Metab 83:2291-2295, 1998

8. Buchfelder M, Nistor R, Fahlbusch R, Huk WJ: The accuracy of CT and MR evaluation of the sella turcica for detection of adrenocorticotropic hormone-secreting adenomas in Cushing disease. AJNR Am J Neuroradiol 14:1183-1190, 1993

9. Burman P, Lethagen A, Ivancev K, Johansson L, Sundin A: Dual bronchial carcinoids and Cushing's syndrome with a paradoxical response to dexamethasone and a false positive outcome of inferior petrosal sinus sampling. Eur J Endocrinol 159:483-488, 2008

10. Castinetti F, Morange I, Dufour H, Jaquet P, Conte-Devolx B, Girard N, et al: Desmopressin test during petrosal sinus sampling: a valuable tool to discriminate pituitary or ectopic ACTH-dependent Cushing's syndrome. Eur J Endocrinol 157:271-277, 2007

11. Daousi C, Nixon T, Javadpour M, Hayden K, MacFarlane IA: Inferior petrosal sinus ACTH and prolactin responses to $\mathrm{CRH}$ in ACTH-dependent Cushing's syndrome: a single centre experience from the United Kingdom. Pituitary 13:95-104, 2010

12. Dichek HL, Nieman LK, Oldfield EH, Pass HI, Malley JD, Cutler GB Jr: A comparison of the standard high dose dexamethasone suppression test and the overnight 8-mg dexamethasone suppression test for the differential diagnosis of adrenocorticotropin-dependent Cushing's syndrome. J Clin Endocrinol Metab 78:418-422, 1994

13. Doglietto F, Maira G: Cushing disease and negative magnetic resonance imaging finding: a diagnostic and therapeutic challenge. World Neurosurg 77:445-447, 2012

14. Findling JW, Aron DC, Tyrrell JB, Shinsako JH, Fitzgerald PA, Norman D, et al: Selective venous sampling for ACTH in Cushing's syndrome: differentiation between Cushing disease and the ectopic ACTH syndrome. Ann Intern Med 94:647-652, 1981

15. Findling JW, Kehoe ME, Raff H: Identification of patients with Cushing's disease with negative pituitary adrenocorticotropin gradients during inferior petrosal sinus sampling: prolactin as an index of pituitary venous effluent. J Clin Endocrinol Metab 89:6005-6009, 2004

16. Findling JW, Kehoe ME, Shaker JL, Raff H: Routine inferior petrosal sinus sampling in the differential diagnosis of adrenocorticotropin (ACTH)-dependent Cushing's syndrome: early recognition of the occult ectopic ACTH syndrome. $\mathbf{J}$ Clin Endocrinol Metab 73:408-413, 1991

17. Flack MR, Oldfield EH, Cutler GB Jr, Zweig MH, Malley JD, Chrousos GP, et al: Urine free cortisol in the high-dose dexamethasone suppression test for the differential diagnosis of the Cushing syndrome. Ann Intern Med 116:211-217, 1992

18. Grant P, Dworakowska D, Carroll P: Maximizing the accuracy of Inferior petrosal sinus sampling: validation of the use of Prolactin as a marker of pituitary venous effluent in the diagnosis of Cushing's disease. Clin Endocrinol (Oxf) 76:555-559, 2012

19. Hall WA, Luciano MG, Doppman JL, Patronas NJ, Oldfield EH: Pituitary magnetic resonance imaging in normal human volunteers: occult adenomas in the general population. Ann Intern Med 120:817-820, 1994

20. Ilias I, Chang R, Pacák K, Oldfield EH, Wesley R, Doppman J, et al: Jugular venous sampling: an alternative to petrosal sinus sampling for the diagnostic evaluation of adrenocorticotropic hormone-dependent Cushing's syndrome. J Clin Endocrinol Metab 89:3795-3800, 2004

21. Ilias I, Torpy DJ, Pacák K, Mullen N, Wesley RA, Nieman LK: Cushing's syndrome due to ectopic corticotropin secretion: twenty years' experience at the National Institutes of Health. J Clin Endocrinol Metab 90:4955-4962, 2005

22. Invitti C, Pecori Giraldi F, Cavagnini F: Inferior petrosal sinus sampling in patients with Cushing's syndrome and contradictory responses to dynamic testing. Clin Endocrinol (Oxf) 51:255-257, 1999

23. Invitti C, Pecori Giraldi F, de Martin M, Cavagnini F, Study Group of the Italian Society of Endocrinology on the Pathophysiology of the Hypothalamic-Pituitary-Adrenal Axis: Diagnosis and management of Cushing's syndrome: results of an Italian multicentre study. J Clin Endocrinol Metab 84:440-448, 1999

24. Jehle S, Walsh JE, Freda PU, Post KD: Selective use of bilateral inferior petrosal sinus sampling in patients with adrenocorticotropin-dependent Cushing's syndrome prior to transsphenoidal surgery. J Clin Endocrinol Metab 93:4624-4632, 2008

25. Juszczak A, Ertorer ME, Grossman A: The therapy of Cushing's disease in adults and children: an update. Horm Metab Res 45:109-117, 2013

26. Kalgikar AM, Chandratreya SA, Goel A, Shrivastava M, Limaye US, Karvat A, et al: Inferior petrosal sinus sampling in the diagnostic evaluation of Cushing's syndrome: K.E.M. experience. J Assoc Physicians India 53:685-688, 2005

27. Kaltsas GA, Giannulis MG, Newell-Price JD, Dacie JE, Thakkar C, Afshar F, et al: A critical analysis of the value of simultaneous inferior petrosal sinus sampling in Cushing's disease and the occult ectopic adrenocorticotropin syndrome. J Clin Endocrinol Metab 84:487-492, 1999

28. Kaskarelis IS, Tsatalou EG, Benakis SV, Malagari K, Komninos I, Vassiliadi D, et al: Bilateral inferior petrosal sinuses sampling in the routine investigation of Cushing's syndrome: a comparison with MRI. AJR Am J Roentgenol 187:562-570, 2006 (Errata in AJR Am J Roentgenol 188:1170, 2007 and AJR Am J Roentgenol 193:1463, 2009)

29. Landolt AM, Schubiger O, Maurer R, Girard J: The value of inferior petrosal sinus sampling in diagnosis and treatment of Cushing's disease. Clin Endocrinol (Oxf) 40:485-492, 1994

30. Lefournier V, Martinie M, Vasdev A, Bessou P, Passagia JG, Labat-Moleur F, et al: Accuracy of bilateral inferior petrosal or cavernous sinuses sampling in predicting the lateraliza- 
tion of Cushing's disease pituitary microadenoma: influence of catheter position and anatomy of venous drainage. J Clin Endocrinol Metab 88:196-203, 2003

31. Liu C, Lo JC, Dowd CF, Wilson CB, Kunwar S, Aron DC, et al: Cavernous and inferior petrosal sinus sampling in the evaluation of ACTH-dependent Cushing's syndrome. Clin Endocrinol (Oxf) 61:478-486, 2004

32. López J, Barceló B, Lucas T, Salame F, Alameda C, Boronat M, et al: Petrosal sinus sampling for diagnosis of Cushing's disease: evidence of false negative results. Clin Endocrinol (Oxf) 45:147-156, 1996

33. Machado MC, de Sa SV, Domenice S, Fragoso MC, Puglia $\mathrm{P}$ Jr, Pereira MA, et al: The role of desmopressin in bilateral and simultaneous inferior petrosal sinus sampling for differential diagnosis of ACTH-dependent Cushing's syndrome. Clin Endocrinol (Oxf) 66:136-142, 2007

34. Manetti L, Grasso L, Vignali C, Petruzzi P, Lupi I, Genovesi $\mathrm{M}$, et al: Undetectable inferior petrosal sinus levels of PTHrelated peptide $(\mathrm{PTHrP})$ in patients with $\mathrm{ACTH}$-dependent Cushing's disease. J Endocrinol Invest 28:819-821, 2005

35. Miller DL, Doppman JL, Peterman SB, Nieman LK, Oldfield EH, Chang R: Neurologic complications of petrosal sinus sampling. Radiology 185:143-147, 1992

36. Mitsuhashi Y, Nishio A, Kawahara S, Ichinose T, Yamauchi $\mathrm{S}$, Naruse $\mathrm{H}$, et al: Morphologic evaluation of the caudal end of the inferior petrosal sinus using 3D rotational venography. AJNR Am J Neuroradiol 28:1179-1184, 2007

37. Moro M, Putignano P, Losa M, Invitti C, Maraschini C, Cavagnini F: The desmopressin test in the differential diagnosis between Cushing's disease and pseudo-Cushing states. J Clin Endocrinol Metab 85:3569-3574, 2000

38. Mulligan GB, Eray E, Faiman C, Gupta M, Pineyro MM, Makdissi A, et al: Reduction of false-negative results in inferior petrosal sinus sampling with simultaneous prolactin and corticotropin measurement. Endocr Pract 17:33-40, 2011

39. Mulligan GB, Faiman C, Gupta M, Kennedy L, Hatipoglu B, Hui F, et al: Prolactin measurement during inferior petrosal sinus sampling improves the localization of pituitary adenomas in Cushing's disease. Clin Endocrinol (Oxf) 77:268274,2012

40. Nieman LK: Difficulty in the diagnosis of Cushing disease. Nat Clin Pract Endocrinol Metab 2:53-57, 2006

41. Oldfield EH, Doppman JL, Nieman LK, Chrousos GP, Miller DL, Katz DA, et al: Petrosal sinus sampling with and without corticotropin-releasing hormone for the differential diagnosis of Cushing's syndrome. N Engl J Med 325:897-905, 1991

42. Parenti G, Nassi R, Silvestri S, Bianchi S, Valeri A, Manca G, et al: Multi-step approach in a complex case of Cushing's syndrome and medullary thyroid carcinoma. J Endocrinol Invest 29:177-181, 2006

43. Park JW, Park S, Kim JL, Lee HY, Shin JE, Hyun DH, et al: Bilateral inferior petrosal sinus sampling by unilateral femoral venous approach. Neurointervention 6:23-26, 2011

44. Patronas N, Bulakbasi N, Stratakis CA, Lafferty A, Oldfield EH, Doppman J, et al: Spoiled gradient recalled acquisition in the steady state technique is superior to conventional postcontrast spin echo technique for magnetic resonance imaging detection of adrenocorticotropin-secreting pituitary tumors. J Clin Endocrinol Metab 88:1565-1569, 2003

45. Pecori Giraldi F: Recent challenges in the diagnosis of Cushing's syndrome. Horm Res 71 (Suppl 1):123-127, 2009

46. Pecori Giraldi F, Ambrogio AG, Fatti LM, Rubini V, Cozzi G, Scacchi M, et al: Von Willebrand factor and fibrinolytic parameters during the desmopressin test in patients with Cushing's disease. Br J Clin Pharmacol 71:132-136, 2011

47. Pecori Giraldi F, Pagliardini L, Cassarino MF, Losa M, Lasio G, Cavagnini F: Responses to corticotrophin-releasing hormone and dexamethasone in a large series of human adrenocorticotrophic hormone-secreting pituitary adenomas in vitro reveal manifold corticotroph tumoural phenotypes. J Neuroendocrinol 23:1214-1221, 2011

48. Reimondo G, Paccotti P, Minetto M, Termine A, Stura G, Bergui M, et al: The corticotrophin-releasing hormone test is the most reliable noninvasive method to differentiate pituitary from ectopic ACTH secretion in Cushing's syndrome. Clin Endocrinol (Oxf) 58:718-724, 2003

49. Reimondo G, Pia A, Bovio S, Allasino B, Daffara F, Paccotti $\mathrm{P}$, et al: Laboratory differentiation of Cushing's syndrome. Clin Chim Acta 388:5-14, 2008

50. Schulte HM, Mönig H: Hormone measurement in blood from inferior petrosal sinus: clinical and experimental implications. J Endocrinol Invest 16:647-653, 1993

51. Semple PL, Vance ML, Findling J, Laws ER Jr: Transsphenoidal surgery for Cushing's disease: outcome in patients with a normal magnetic resonance imaging scan. Neurosurgery 46:553-559, 2000

52. Sharma ST, Nieman LK: Is prolactin measurement of value during inferior petrosal sinus sampling in patients with adrenocorticotropic hormone-dependent Cushing's Syndrome? J Endocrinol Invest 36:1112-1116, 2013

53. Sharma ST, Raff H, Nieman LK: Prolactin as a marker of successful catheterization during IPSS in patients with ACTH-dependent Cushing's syndrome. J Clin Endocrinol Metab 96:3687-3694, 2011

54. Sheth SA, Mian MK, Neal J, Tritos NA, Nachtigall L, Klibanski A, et al: Transsphenoidal surgery for Cushing disease after nondiagnostic inferior petrosal sinus sampling. Neurosurgery 71:14-22, 2012

55. Shi X, Sun Q, Bian L, Zhao W, Shen J, Wang W, et al: Assessment of bilateral inferior petrosal sinus sampling in the diagnosis and surgical treatment of the ACTH-dependent Cushing's syndrome: a comparison with other tests. Neuroendocrinol Lett 32:865-873, 2011

56. Shiu PC, Hanafee WN, Wilson GH, Rand RW: Cavernous sinus venography. Am J Roentgenol Radium Ther Nucl Med 104:57-62, 1968

57. Tabarin A, Greselle JF, San-Galli F, Leprat F, Caille JM, Latapie JL, et al: Usefulness of the corticotropin-releasing hormone test during bilateral inferior petrosal sinus sampling for the diagnosis of Cushing's disease. J Clin Endocrinol Metab 73:53-59, 1991

58. Tani Y, Sugiyama T, Hirooka S, Izumiyama H, Hirata Y: Ectopic ACTH syndrome caused by bronchial carcinoid tumor indistinguishable from Cushing's disease. Endocr J 57:679-686, 2010

59. Teramoto A, Yoshida Y, Sanno N, Nemoto S: Cavernous sinus sampling in patients with adrenocorticotrophic hormonedependent Cushing's syndrome with emphasis on inter- and intracavernous adrenocorticotrophic hormone gradients. J Neurosurg 89:762-768, 1998

60. Testa RM, Albiger N, Occhi G, Sanguin F, Scanarini M, Berlucchi S, et al: The usefulness of combined biochemical tests in the diagnosis of Cushing's disease with negative pituitary magnetic resonance imaging. Eur J Endocrinol 156:241248,2007

61. Tomycz ND, Horowitz MB: Inferior petrosal sinus sampling in the diagnosis of sellar neuropathology. Neurosurg Clin N Am 20:361-367, 2009

62. Trulea M, Patey M, Chaufour-Higel B, Bouquigny F, Longuebray A, Rousseaux P, et al: An unusual case of ectopic adrenocorticotropin secretion. J Clin Endocrinol Metab 94:384-385, 2009

63. Tsagarakis S, Vassiliadi D, Kaskarelis IS, Komninos J, Souvatzoglou $\mathrm{E}$, Thalassinos $\mathrm{N}$ : The application of the combined corticotropin-releasing hormone plus desmopressin stimulation during petrosal sinus sampling is both sensitive and specific in differentiating patients with Cushing's disease from patients with the occult ectopic adrenocorticotropin syndrome. J Clin Endocrinol Metab 92:2080-2086, 2007 
64. Wajchenberg BL, Mendonca BB, Liberman B, Pereira MA, Carneiro PC, Wakamatsu A, et al: Ectopic adrenocorticotropic hormone syndrome. Endocr Rev 15:752-787, 1994

65. Watanobe H, Tamura T, Habu S, Kakizaki Y, Kohsaka A, Suda T: Measurement of cytokines in the cavernous sinus plasma from patients with Cushing's disease. Neuropeptides 32:119-123, 1998

66. Wiggam MI, Heaney AP, McIlrath EM, McCance DR, Sheridan B, Hadden DR, et al: Bilateral inferior petrosal sinus sampling in the differential diagnosis of adrenocorticotropindependent Cushing's syndrome: a comparison with other diagnostic tests. J Clin Endocrinol Metab 85:1525-1532, 2000

67. Wind JJ, Lonser RR, Nieman LK, DeVroom HL, Chang R, Oldfield EH: The lateralization accuracy of inferior petrosal sinus sampling in 501 patients with Cushing's disease. J Clin Endocrinol Metab 98:2285-2293, 2013

68. Yamamoto Y, Davis DH, Nippoldt TB, Young WF Jr, Huston J III, Parisi JE: False-positive inferior petrosal sinus sampling in the diagnosis of Cushing's disease. Report of two cases. J Neurosurg 83:1087-1091, 1995

69. Young J, Deneux C, Grino M, Oliver C, Chanson P, Schaison G: Pitfall of petrosal sinus sampling in a Cushing's syndrome secondary to ectopic adrenocorticotropin-corticotropin re- leasing hormone (ACTH-CRH) secretion. J Clin Endocrinol Metab 83:305-308, 1998

70. Zarrilli L, Colao A, Merola B, La Tessa G, Spaziante R, Tripodi FS, et al: Corticotropin-releasing hormone test: improvement of the diagnostic accuracy of simultaneous and bilateral inferior petrosal sinus sampling in patients with Cushing syndrome. World J Surg 19:150-153, 1995

\section{Author Contributions}

Conception and design: Pecori Giraldi, Cavallo, Tortora, Cappabianca, Mantero. Acquisition of data: Pecori Giraldi. Analysis and interpretation of data: Pecori Giraldi, Cavallo, Tortora. Drafting the article: all authors. Critically revising the article: Pecori Giraldi, Cavallo, Tortora, Cappabianca, Mantero. Reviewed submitted version of manuscript: all authors. Approved the final version of the manuscript on behalf of all authors: Pecori Giraldi.

\section{Correspondence}

Francesca Pecori Giraldi, Department of Clinical Sciences and Community Health, University of Milan, Neuroendocrinology Research Laboratory, Istituto Auxologico Italiano, Via Zucchi 18, Cusano Milanino 20095, Italy. email: fpg@auxologico.it. 